\title{
Adherence to the Danish food-based dietary guidelines and risk of myocardial infarction: a cohort study
}

\author{
Camilla Plambeck Hansen ${ }^{1, *}$, Kim Overvad ${ }^{1,2}$, Inge Tetens ${ }^{3}$, Anne Tiønneland ${ }^{4}$, \\ Erik Thorlund Parner ${ }^{5}$, Marianne Uhre Jakobsen ${ }^{1,6}$ and Christina Catherine Dahm ${ }^{1}$ \\ 'Section for Epidemiology, Department of Public Health, Aarhus University, Bartholins Allé 2, DK-8000 Aarhus C, \\ Denmark: ${ }^{2}$ Department of Cardiology, Aalborg University Hospital, Aalborg, Denmark: ${ }^{3}$ Centre for Good Older \\ Lives, Department of Nutrition, Exercise and Sports, University of Copenhagen, Copenhagen, Denmark: \\ ${ }^{4}$ Danish Cancer Society Research Center, Copenhagen, Denmark: ${ }^{5}$ Section for Biostatistics, Department of Public \\ Health, Aarhus University, Aarhus, Denmark: ${ }^{6}$ National Food Institute, Division for Diet, Disease Prevention and \\ Toxicology, Kgs. Lyngby, Denmark
}

Submitted 22 December 2016: Final revision received 16 November 2017: Accepted 21 November 2017: First published online 14 January 2018

\begin{abstract}
Objective: A direct way to evaluate food-based dietary guidelines is to assess if adherence is associated with development of non-communicable diseases. Thus, the objective was to develop an index to assess adherence to the 2013 Danish food-based dietary guidelines and to investigate the association between adherence to the index and risk of myocardial infarction (MI).

Design: Population-based cohort study with recruitment of participants in 1993-1997. Information on dietary intake was collected at baseline using an FFQ and an index ranging from 0 to 6 points was created to assess adherence to the 2013 Danish food-based dietary guidelines. MI cases were identified by record linkage to the Danish National Patient Register and the Causes of Death Register. Cox proportional hazards models were used to estimate hazard ratios (HR) of MI.

Setting: Greater areas of Aarhus and Copenhagen, Denmark.

Subjects: Men and women aged $50-64$ years ( $n$ 55 021) from the Diet, Cancer and Health study.

Results: A total of 3046 participants were diagnosed with first-time MI during a median follow-up of 16.9 years. A higher Danish Dietary Guidelines Index score was associated with a lower risk of MI. After adjustment for potential confounders, the hazard of MI was $13 \%$ lower among men with a score of $3-<4$ ( HR $=0 \cdot 87$; $95 \%$ CI $0.78,0.96)$ compared with men with a score of $<3$. The corresponding HR among women was 0.76 (95\% CI 0.63, 0.93).

Conclusions: Adherence to the 2013 Danish food-based dietary guidelines was inversely associated with risk of MI.
\end{abstract}

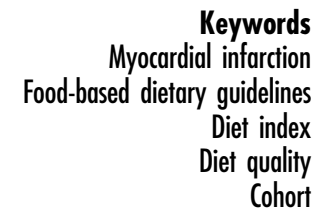

Food-based dietary guidelines are recommendations on what to eat in terms of foods, rather than nutrients, targeting the general public and using language and symbols that are easy to understand ${ }^{(1)}$. Promotion of better health in the population is the ultimate goal of dietary guidelines, and the FAO and WHO have advocated the use of food-based dietary guidelines for more than two decades ${ }^{(1,2)}$. In Denmark, national food-based dietary guidelines were introduced in the 1970s and have since been updated several times, most recently in 2013. The 2013 update of the Danish food-based dietary guidelines was based on the current scientific evidence for the relationship between foods and risk of non-communicable diseases ${ }^{(3)}$ and on the Nordic Nutrition Recommendations $2012^{(4)}$. The ten guidelines cover recommendations regarding fruits and vegetables, fish, whole grains, meat, dairy products, saturated fat, salt, sugar, water, diet variety and physical activity $(\text { Table } 1)^{(5)}$.

Diet quality indices based on the 2005 edition of the Danish food-based dietary guidelines have previously been associated with both macro- and micronutrient intakes in studies using data from the national representative dietary survey ${ }^{(6-9)}$. These studies showed that compliance with the national food-based dietary guidelines was fairly low in the Danish population ${ }^{(6,7)}$. For 
Table 1 Diet quality index based on the 2013 Danish food-based dietary guidelines

\begin{tabular}{|c|c|c|c|c|}
\hline Dietary guideline & Index component & $\begin{array}{l}\text { Criteria for minimum } \\
\text { score }(0)\end{array}$ & $\begin{array}{l}\text { Criteria for maximum } \\
\text { score (1) }\end{array}$ & $\begin{array}{l}\text { Proportion of study } \\
\text { population with } \\
\text { maximum score }\end{array}$ \\
\hline $\begin{array}{c}\text { Eat a variety of foods, but not too } \\
\text { much, and be physically active }\end{array}$ & (not included) & - & - & - \\
\hline $\begin{array}{l}\text { Eat fruits and lots of vegetables } \\
\text { (6 portions, approx. } 600 \mathrm{~g}, \\
\text { per day, at least half of these } \\
\text { should be vegetables) }\end{array}$ & $\begin{array}{l}\text { Minimum } 600 \mathrm{~g} \text { fruits and vegetables/ } \\
\mathrm{d} \text { including up to } 100 \mathrm{ml} \text { juice and } \\
\text { minimum } 300 \mathrm{~g} \text { vegetables/d } \\
\text { (excluding mushrooms) }\end{array}$ & $\begin{array}{l}0 \mathrm{~g} \text { fruit and } \\
\text { vegetables/d }\end{array}$ & $\begin{array}{l}\geq 600 \mathrm{~g} \text { fruit and } \\
\quad \text { vegetables } / \mathrm{d} \\
\text { including } \geq 300 \mathrm{~g} \\
\text { vegetables } / \mathrm{d}\end{array}$ & $6.0 \%$ \\
\hline $\begin{array}{l}\text { Eat more fish (minimum } 350 \mathrm{~g} \text { per } \\
\text { week, including approx. } 200 \mathrm{~g} \\
\text { fatty fish) }\end{array}$ & $\begin{array}{l}\text { Minimum } 350 \mathrm{~g} / \mathrm{week} \text { including } \\
\text { minimum } 200 \mathrm{~g} \text { fatty fish/week }\end{array}$ & $0 \mathrm{~g} \mathrm{fish} /$ week & $\begin{array}{l}\geq 350 \mathrm{~g} \text { fish } / \text { week } \\
\text { including } \geq 200 \mathrm{~g} \\
\text { fatty fish/week }\end{array}$ & $14.8 \%$ \\
\hline $\begin{array}{l}\text { Choose whole grains (minimum } \\
75 \mathrm{~g} \text { whole grains per day) }\end{array}$ & Minimum $75 \mathrm{~g}$ whole grains $/ \mathrm{d}$ & $0 \mathrm{~g}$ whole grains $/ \mathrm{d}$ & $\geq 75 \mathrm{~g}$ whole grains $/ \mathrm{d}$ & $8 \cdot 1 \%$ \\
\hline $\begin{array}{l}\text { Choose lean meats and cold meats } \\
\text { (maximum } 10 \% \text { fat; maximum } \\
500 \mathrm{~g} \text { red and processed meat } \\
\text { per week) }\end{array}$ & $\begin{array}{l}\text { Maximum } 500 \mathrm{~g} \text { red and processed } \\
\text { meat } / \text { week }\end{array}$ & $\begin{array}{l}\geq 1000 \mathrm{~g} \text { red or } \\
\text { processed meat/ } \\
\text { week }\end{array}$ & $\begin{array}{l}\leq 500 \mathrm{~g} \text { red or } \\
\text { processed meat/ } \\
\text { week }\end{array}$ & $21 \cdot 3 \%$ \\
\hline $\begin{array}{l}\text { Choose low-fat dairy products } \\
\text { (cheese maximum } 17 \% \text { fat, } \\
\text { approx. } 25 \mathrm{~g} \text { per day; milk and } \\
\text { other dairy products maximum } \\
0.7 \% \text { fat, } 1 / 4-1 / 2 \text { litre dairy products } \\
\text { per day) }\end{array}$ & (not included) & - & - & - \\
\hline $\begin{array}{l}\text { Eat less saturated fat } \\
\text { Eat foods with less salt }\end{array}$ & $\begin{array}{l}\text { Maximum } 10 \mathrm{E} \% \text { from SFA } \\
\text { (not included) }\end{array}$ & $\geq 20 \mathrm{E} \%$ from SFA & $<10 \mathrm{E} \%$ from SFA & $\begin{array}{c}10 \cdot 1 \% \\
-\end{array}$ \\
\hline Eat less sugar & Maximum $10 \mathrm{E} \%$ from added sugar & $\begin{array}{l}\geq 20 \mathrm{E} \% \text { from added } \\
\text { sugar }\end{array}$ & $\begin{array}{l}<10 \mathrm{E} \% \text { from added } \\
\text { sugar }\end{array}$ & $84 \cdot 2 \%$ \\
\hline Drink water & (not included) & - & - & - \\
\hline
\end{tabular}

$\mathrm{E} \%$, energy percentage.

example, only $5 \%$ complied with the guideline to reduce saturated fat intake to less than $10 \%$ of energy and only $13 \%$ consumed the recommended daily amount of dietary fibre of $3 \mathrm{~g} / \mathrm{MJ}^{(7)}$. However, the most direct way to evaluate dietary guidelines is to investigate if adherence to the guidelines is associated with better health ${ }^{(10)}$. While trials may provide essential information on the effects of dietary guidelines on short-term health outcomes like blood pressure and other biomarkers of disease risk, randomised controlled trials of dietary patterns and chronic diseases like IHD have proved difficult to conduct due to low compliance ${ }^{(10)}$. Observational studies may thus contribute important information about the value of dietary guidelines in promoting better health and preventing non-communicable diseases. Diet quality measured with an index based in part on indices of overall diet quality and in part on previous editions of the Danish food-based dietary guidelines has been associated with CVD risk factors in a cross-sectional study, whereas no association was observed with risk of $\mathrm{CHD}$ in a cohort study ${ }^{(11,12)}$.

The aim of the present study was to develop an index to assess adherence to the 2013 Danish food-based dietary guidelines and to investigate if higher adherence to the guidelines was associated with a lower risk of myocardial infarction (MI), a leading cause of morbidity and mortality ${ }^{(13)}$, in a large follow-up study of both men and women.

\section{Participants and methods}

\section{Study design and population}

The present study was based on data from the Danish follow-up study Diet, Cancer and Health. From December 1993 to May 1997, all men and women aged 50-64 years, born in Denmark, living in the greater areas of Aarhus or Copenhagen and with no previous cancer diagnosis registered in the Danish Cancer Registry were invited to participate in the study ( $n 160725)$. In total, 57053 (35\%) participants were recruited (Fig. 1). At baseline, the participants completed an FFQ enclosed with the invitation and they visited one of the study clinics. In the study clinic, the participants filled in a questionnaire about lifestyle and health and they underwent a physical examination including anthropometric measurements. The study design and measurement procedures have been described in detail by Tjønneland et al. ${ }^{(14)}$.

\section{Dietary assessment}

A 192-item semi-quantitative FFQ, which had been specifically developed for the Diet, Cancer and Health cohort, was mailed to the participants prior to the visit at the study clinic ${ }^{(15)}$. The participants were asked to report their average intake of different food and beverage items over the previous 12 months, ranging from never to eight times or more per day. The FFQ was processed by optical scanning at the study centres and checked for reading 


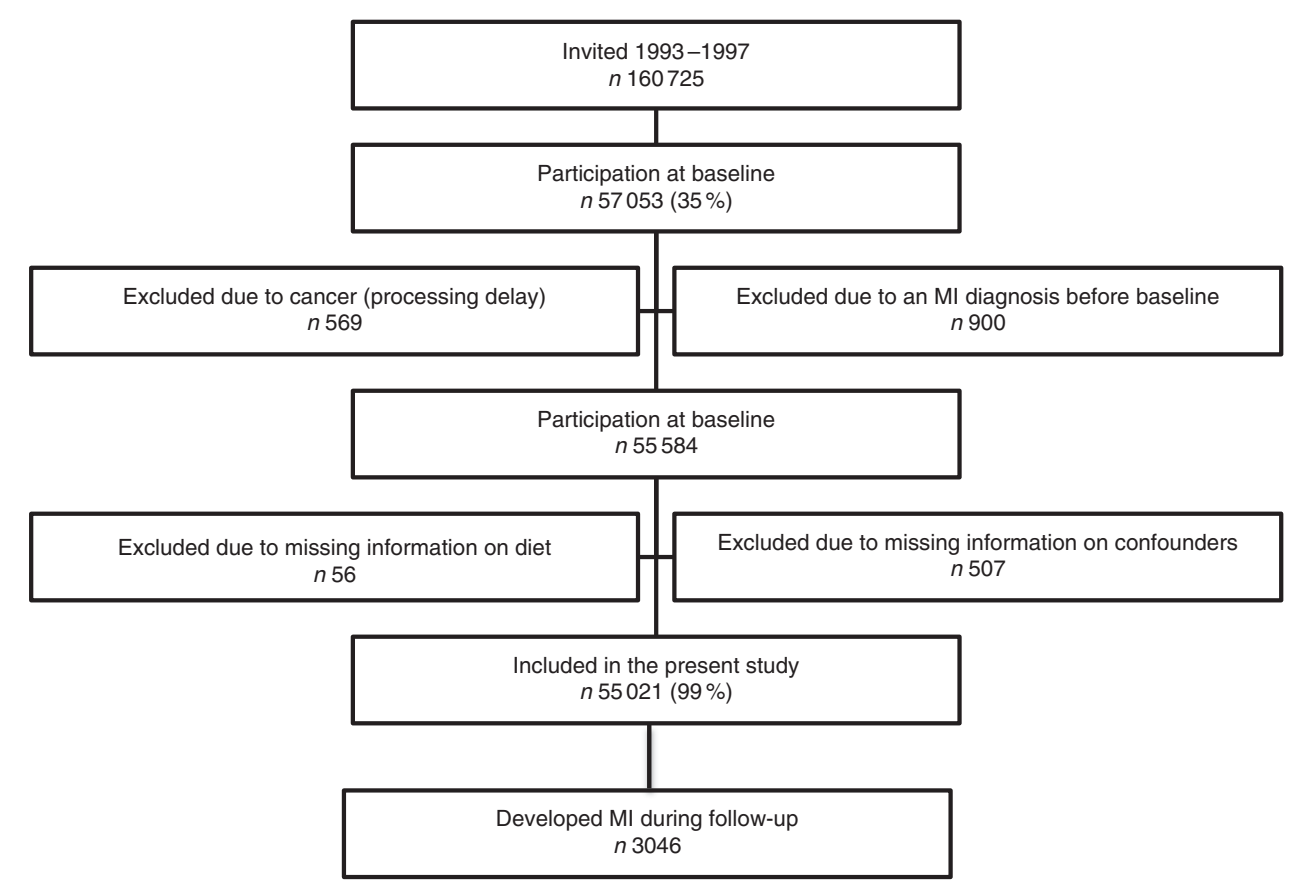

Fig. 1 Flowchart of the study population of Danish men and women from the Diet, Cancer and Health study (MI, myocardial infarction)

errors and missing information. All unclear information was then clarified with the participant during a computerguided interview. The software program FoodCalc (http://www.ibt.ku.dk/jesper/foodcalc/) based on the Danish food composition tables ${ }^{(16)}$ was used to calculate average daily intakes of foods and nutrients using standardised recipes and portion sizes ${ }^{(17)}$. The FFQ was validated against two $7 \mathrm{~d}$ weighed diet records ${ }^{(18)}$. Classification of the nutrient intake distributions into quintiles was used to evaluate the agreement between the two instruments. On average, $70 \%$ of subjects were classified in the same $( \pm 1)$ quintile. Whole grains were defined in accordance with the definition by the American Association of Cereal Chemists ${ }^{(19)}$ and intake of whole grains in absolute amounts $(\mathrm{g} / \mathrm{d})$ was estimated based on information on the wholegrain content in specific products reported in $24 \mathrm{~h}$ dietary recalls conducted in a random sub-sample of participants. A detailed description of the estimation of whole grains intake is available elsewhere $^{(20)}$.

An index was developed to assess adherence to the current edition of the national Danish food-based dietary guidelines from 2013 (Table 1). This index, the Danish Dietary Guidelines Index, was constructed in concordance with the approach used by Knudsen et al. ${ }^{(6)}$ when constructing an index based on the 2005 Danish food-based dietary guidelines with the addition of index components for intakes of whole grains and red meat. The following foods and nutrients were included in the new index: intake of fruits and vegetables, intake of fish, intake of whole grains, intake of red and processed meat, energy contribution from saturated fat and energy contribution from added sugar.

Intake of potatoes and mushrooms did not contribute to the intake of vegetables and up to $100 \mathrm{~g}$ of fruits could be replaced by juice ${ }^{(21)}$. The 2013 Danish food-based dietary guidelines do not specify how much saturated fat and added sugar may be allowed in a healthy diet. However, the Nordic Nutrition Recommendations state that both saturated fat and added sugar should contribute less than $10 \%$ of total energy intake each, which was therefore used as cut-off when constructing the index components for these two guidelines ${ }^{(4)}$. The percentages of energy from saturated fat and added sugar were calculated based on total energy from carbohydrates, proteins and fat, excluding alcohol.

The guidelines 'Choose low-fat dairy products', 'Eat food with less salt', 'Drink water' and 'Eat a variety of foods, but not too much, and be physically active' were not included in the index. Most fat in milk and other dairy products is saturated fat. Thus, intake of fat from dairy products is reflected in the total intake of saturated fat, which is included as a separate index component. The guideline on meat advises not to consume more than $500 \mathrm{~g}$ of red and processed meat in total per week and this recommendation is included as a component in the Danish Dietary Guidelines Index. However, an index component has not been constructed for the recommendation to choose lean meat and cold meats, because the intake of fat from meat products is also reflected in the total intake of saturated fat. If the recommendation to drink water instead of soft drinks is followed, this should be reflected 
in a lower intake of added sugar. Guidelines on alcohol consumption are not part of the national Danish dietary guidelines and therefore alcohol is not included in the index. Dietary variety may be calculated as the number of different foods consumed during a given time period ${ }^{(22,23)}$. However, it would be possible to obtain a high total Danish Dietary Guidelines Index score only with a varied diet, since the index contains multiple items that capture the intakes of different foods or nutrients ${ }^{(23)}$. Therefore, we decided not to include an item for dietary variety in the Danish Dietary Guidelines Index. The guideline on salt intake was also not included in the index since $\mathrm{Na}$ intake was poorly estimated in the FFQ.

Items were scored proportionally to compliance with the dietary guidelines and the score for each item ranged from 0 to 1 , with 1 point assigned to an intake complying with the corresponding dietary guideline (Table 1). Scores were calculated as the ratio between the actual intake and the recommended intake for guidelines with a minimum recommended intake, and an item score of 1 point was assigned if the guideline was fully met. Thus, no extra points were given for eating more than the minimum recommended amount. For foods and nutrients with an upper limit of recommended intake, scores were calculated as 1 minus the difference between actual intake and recommended intake divided by the recommended intake ([1 - (actual intake - recommended intake)]/recommended intake). Negative item scores were replaced by 0 to ensure a score range between 0 and 1 for guidelines with maximum recommended intakes. Thus, participants consuming at least twice the maximum recommended intake would receive a score of 0 points. The guidelines 'Eat fruits and lots of vegetables' and 'Eat more fish' consisted of a recommended lower limit of total intake and a recommended lower limit of intake of vegetables and fatty fish, respectively. The scores for these two guidelines were constructed as a weighted sum of the subcomponents using equal weights. Thus, the score for the guideline 'Eat fruits and lots of vegetables' was calculated as follows: score $=[($ total intake fruit + vegetables $/ 600 \mathrm{~g}) \times 0 \cdot 5]+\left[\right.$ (intake $_{\text {vege- }}$ tables $/ 300 \mathrm{~g}) \times 0.5$ ]. Similarly, the score for the guideline 'Eat more fish' was calculated as follows: score $=\left[\left(\right.\right.$ intake $_{\text {total fish }} /$ $350 \mathrm{~g}) \times 0.5]+\left[\right.$ intake $_{\text {fatty }}$ fish $\left.\left./ 200 \mathrm{~g}\right) \times 0.5\right]$.

The individual guidelines of the 2013 Danish foodbased dietary guidelines are not prioritised or ranked; therefore, no weighting was applied when constructing the index and the scores of the individual items were simply summed. The total score of Danish Dietary Guidelines Index thus ranged from 0 points (no compliance) to 6 points (full compliance).

\section{Outcome}

The outcome was incident non-fatal and fatal MI (International Classification of Diseases, revision 8 (ICD-8) codes: 410-410.99; International Classification of Diseases, revision 10 (ICD-10) codes: I21.0-I21.9). Participants with sudden cardiac death (ICD-8 code: 427.27; ICD-10 codes: I46.0-I46.9) were also included as cases if the cardiac death was believed to be caused by MI. Cases were identified by record linkage to the Danish National Patient Register and the Danish Causes of Death Register using the unique identification number assigned to all Danish citizens ${ }^{(24,25)}$. From enrolment and until 31 December 2003, cases were validated by review of medical records in accordance with the guidelines of the American Heart Association and the European Society for Cardiology ${ }^{(26)}$. From 1 January 2004 and until end of follow-up (2 July 2013), and for participants whose medical records had not been available in the previous period, participants with an MI diagnosis from a hospital ward were included as cases without validation, as the positive predictive value of these diagnoses was $>90 \%{ }^{(27)}$.

\section{Covariates}

Information on smoking, physical activity, education and history of hypertension, hypercholesterolaemia and diabetes was obtained from the self-administered lifestyle questionnaire at baseline. Smoking was reported as 'never', 'former' or 'current'; duration of smoking in years; and the number of cigarettes, cigars, cheroots and tobacco pipes smoked per day. For current smokers, tobacco consumption was calculated in grams per day by using conversion factors of 1.0 for cigarettes, 4.5 for cigars and 3.0 for cheroots and tobacco pipes. Leisure-time physical activity during the past year was reported as hours per week engaged in walking, gardening, housework, home maintenance, biking and sports during summer and winter. Moderate-to-vigorous leisure-time physical activity was calculated as the average number of hours per week spent on biking and sports during the whole year. Length of education was reported in predefined categories $(\leq 7$ years, $8-10$ years and $>10$ years). History of hypertension, hypercholesterolaemia and diabetes was recorded as 'yes', 'no' or 'don't know' and whether medication was taken for the condition or not ('yes', 'no'). Participants were classified as having the condition if they answered 'yes' to having the condition or to taking medication for it.

Trained laboratory technicians obtained baseline measures of height, body weight and waist circumference. Height was measured to the nearest $0.5 \mathrm{~cm}$ when participants were standing without shoes. Body weight was measured with a digital scale with participants wearing light underwear and recorded to the nearest $100 \mathrm{~g}$. Waist circumference was measured at the narrowest circumference between the lower rib and the iliac crest (the natural waist), or if waist narrowing was indeterminable, halfway between the lower rib and the iliac crest, and recorded to the nearest $0.5 \mathrm{~cm}$.

\section{Exclusions}

Participants with a cancer diagnosis before baseline, which had not been registered in the Danish Cancer Registry at the time of invitation due to processing delay, were excluded according to the inclusion criteria. 
Furthermore, participants with a diagnosis of MI before enrolment were excluded. Finally, participants with missing information on dietary intake or any of the potential confounders were excluded.

\section{Statistical analyses}

The Cox proportional hazards model was employed to estimate hazard ratios (HR) with $95 \%$ CI for the association between the Danish Dietary Guidelines Index and incidence of MI. The analyses were conducted in men and women separately. We used age as the underlying time scale and all analyses were adjusted for baseline age and stratified by tertiles of date of enrolment since the assumption of conditional independence between entry time, i.e. age and date at entry in the Diet, Cancer and Health cohort, and event time underlying Cox survival analyses was not fulfilled in all models. Participants were considered at risk from the date of enrolment into the Diet, Cancer and Health study until the time of MI ( $n$ 3046), death due to other causes ( $n$ 7968), emigration ( $n$ 349), change in personal identification number $(n 2)$ or 2 July 2013, whichever came first.

For the analyses, the Danish Dietary Guidelines Index was categorised into four groups: $<3$ points; $3-<4$ points; $4-<5$ points; and $\geq 5$ points. The two middle categories had a range of 1 point corresponding to compliance with one extra guideline. Due to few participants with scores $<3$ and $\geq 5$ points, respectively, the lowest and the highest category of adherence covered a broader score range than the two middle categories to secure sufficient numbers of cases in each category.

Potential confounders were selected a priori based on established risk factors for CVD. Model 1a included adjustment for age and enrolment date only, while the following variables were included as potential confounders in model 1b: alcohol intake (yes, no; g/d), leisure-time physical activity (h/week), smoking (never, former, current smoker $<15 \mathrm{~g}$ tobacco/d, 15-25 g tobacco/ $\mathrm{d},>25 \mathrm{~g}$ tobacco/d) and education ( $\leq 7$ years, $8-10$ years, $>10$ years). Finally, model 2 included adjustments for the following potential intermediate variables: BMI $\left(\mathrm{kg} / \mathrm{m}^{2}\right)$, waist circumference $(\mathrm{cm})$ and self-reported history of hypertension (yes, no, don't know), hypercholesterolaemia (yes, no, don't know) and diabetes mellitus (yes, no, don't know).

All continuous covariates were included in the models using restricted cubic splines with three knots placed at the 10th, 50th and 90th percentiles as recommended by Harrel $^{(28)}$. The Danish Dietary Guidelines Index was analysed both as a categorical and as a continuous variable. When analysed as a continuous variable, the Danish Dietary Guidelines Index was modelled using restricted cubic splines with three knots and a Wald test was used to test for non-linearity by testing if the second spline parameter was statistically significantly different from zero. Since nonlinearity was detected, linear estimates are not provided.
The proportional hazards assumption was tested in each tertile of enrolment date with log-rank tests based on Schoenfeld residuals and further assessed with log-log plots. No considerable violations were found. Analysis time was also split into three age periods (50-64 years, 65-74 years and $\geq 75$ years) so that participants contributed to successive periods over the course of followup, starting with 50-64 years of age at recruitment. The analyses were then repeated to investigate if the association between adherence to the 2013 Danish food-based dietary guidelines and incidence of MI differed across age.

In supplementary analyses, the associations between the individual index components and risk of MI were investigated. The score of each index component was dichotomised according to compliance (no/yes) and the items were analysed in mutually adjusted models. We also conducted supplementary analyses of the association between the Danish Dietary Guidelines Index and risk of MI stratified by baseline self-reported disease.

All reported tests are two-tailed and $P$ values below 0.05 were considered statistically significant. The statistical software package Stata version 13.1 was used to conduct the analyses.

\section{Results}

A flowchart of the study population is shown in Fig. 1. A total of 57053 subjects were recruited at baseline; however, 569 subjects were later removed from the cohort due to a cancer diagnosis prior to enrolment. Nine hundred participants were excluded due to an MI diagnosis before baseline, information on dietary intake was missing for fifty-six participants and 507 participants were excluded due to missing information on potential confounders. Thus, 55021 subjects ( $53 \%$ women) were included in the present study. During a median follow-up of 16.9 years, 3046 participants were diagnosed with a first-time MI.

Intakes of fruit and vegetables, fish, whole grains, vegetable oils and low-fat dairy were positively associated with the Danish Dietary Guidelines Index, whereas intakes of red and processed meat, saturated fat, butter and added sugar were inversely associated with the Danish Dietary Guidelines Index (see online supplementary material, Supplemental Table 1). No clear tendencies were observed for intakes of salt and high-fat dairy. The correlation coefficients between the individual components and the total Danish Dietary Guidelines Index ranged from $r=0.43$ to $r=0.62$ for all index components except the added sugar component, where the correlation with the total index was $r=0 \cdot 28$ (Supplemental Table 2). The correlations between the individual index components ranged between $r=-0.20$ and $r=0.34$. Compliance with the guidelines was low except for the guideline regarding added sugar (Supplemental Table 1). The proportion of men was lower across higher Danish Dietary Guidelines 
Index scores. Thus, men composed $67 \%$ of the participants with a score of $<3$ but only $24 \%$ of the participants with a score of $\geq 5$. The maximum score of the Danish Dietary Guidelines Index was obtained by only $0.04 \%$ of the cohort, while $6.8 \%$ had a total score of $\geq 5$. In general, the proportion of subjects with a healthy lifestyle was higher across higher Danish Dietary Guidelines Index scores (Supplementary Table 1). For example, 53\% of the male participants with a score of $<3$ were current smokers compared with $21 \%$ of the male participants with a Danish Dietary Guidelines Index score of $\geq 5$. In women, the equivalent proportions were 52 and $19 \%$, respectively.

Characteristics of the study population are shown in Table 2. The median Danish Dietary Guidelines Index score was 3.6 (5th-95th percentile: $2.4-4.9$ ) among men and 4.0 (5th-95th percentile: $2 \cdot 7-5 \cdot 2$ ) among women. Intakes of fruits and vegetables, fish, whole grains and low-fat dairy were slightly lower in cases compared with the total study population, whereas intakes of red and processed meat and saturated fat were slightly higher among cases (data not shown). In addition, the median BMI and waist circumference were higher among cases and the proportion of current smokers and the proportion with $\leq 7$ years of education were higher in cases compared with the total study population.

In men, a statistically significant inverse association was observed between the Danish Dietary Guidelines Index and incidence of MI ( $P=0.009$; Table 3). After adjustment for potential confounders, the hazard of MI was $13 \%$ lower among men with a Danish Dietary Guidelines Index score of $3-<4(\mathrm{HR}=0.87 ; 95 \% \mathrm{CI} 0.78,0.96)$ and $18 \%$ lower among men with a score of $4-<5(\mathrm{HR}=0.82 ; 95 \%$ CI $0.72,0.93)$ compared with men with a score of $<3$ (model 1b). The corresponding HR for MI in women with a score of $3-<4$ and $4-<5$ were 0.76 (95\% CI $0.63,0.93)$ and 0.74 (95\% CI $0 \cdot 60,0.91$ ), respectively (Table 4 ). However, there was no statistically significant linear trend across the Danish Dietary Guidelines Index in women $(P=0 \cdot 214)$. In both men and women, participants with a score of $\geq 5$ had a $10 \%$ lower hazard of MI compared with participants with a score of $<3$; however, the HR were not statistically significant. When modelling the association between the Danish Dietary Guidelines Index and incidence of MI using restricted cubic splines, an inverse association was observed up to a score of 4, where the association levelled off (Fig. 2). A similar pattern was observed in men, but less distinct, and the association between the Danish Dietary Guidelines Index and risk of MI was statistically significantly non-linear only among women (women, $P=0.021$; men, $P=0 \cdot 088$ ).

In general, the estimates in women were slightly lower than in men. However, the CI were also wider in women.

The association between the Danish Dietary Guidelines Index and risk of MI was also present after adjustment for potential intermediate variables (model 2; Tables 3 and 4).

When analysis time was split into three age periods, stronger inverse associations were found in the age period
$<65$ years than in the age period $65-74$ years, and in the age period $\geq 75$ years positive associations between the Danish Dietary Guidelines Index and risk of MI were observed, albeit with wide CI (see online supplementary material, Supplemental Tables 3 and 4).

In men, statistically significant inverse associations were observed between the guidelines concerning whole grains and sugar and risk of MI (see online supplementary material, Supplemental Table 5). In women, a statistically significant positive association was observed between compliance with the guideline to eat less saturated fat and risk of MI (Supplemental Table 6). No other significant association between individual guidelines and risk of MI was observed.

In the supplementary analyses stratified by baseline self-reported disease, the same patterns were observed as in the main analyses (see online supplementary material, Supplemental Table 7).

\section{Discussion}

In the present study, we found that higher adherence to the 2013 Danish food-based dietary guidelines was associated with a lower risk of MI. The inverse association was observed up to a Danish Dietary Guidelines Index score of 4, which corresponds to full compliance with four out of six guidelines, above which the association levelled off.

The strengths of our study include the follow-up design, detailed information on potential confounders and nearly complete ascertainment of vital status. The negligible censoring due to unknown vital status (0.6\%), which was due to emigration, limits the concern for selection bias.

A potential limitation of our study is the dietary assessment, which was conducted using a selfadministered FFQ at enrolment into the study. Some misclassification of dietary intake is inevitable, but due to the follow-up design, any misclassification was probably nondifferential with respect to the outcome, which generally leads to an underestimation of the true association. However, diet was assessed once only and participants may have changed their dietary intake during follow-up. If changes in dietary intake are associated with risk of MI, it could bias our results. Most likely people who perceive themselves as being at higher risk of CVD would try to adopt a healthier diet, thus leading to an underestimation of the risk associated with consuming a less healthy diet at entry to the study. Another limitation was the low validity of the information on salt intake in the study population, which meant that an item for the recommendation to reduce salt intake was not included in the Danish Dietary Guidelines Index ${ }^{(29)}$.

As in all observational studies, residual confounding cannot be ruled out. However, our data allowed profound adjustment for many potential confounders. Moreover, all continuous confounders were modelled using restricted 
Table 2 Characteristics of the total study population of Danish men and women ( $n 55021)$ from the Diet, Cancer and Health study

\begin{tabular}{|c|c|c|c|c|}
\hline & \multicolumn{2}{|c|}{ Men ( $n$ 25 961) } & \multicolumn{2}{|c|}{ Women (n 29 060) } \\
\hline & Median & P5-P95 & Median & P5-P95 \\
\hline Danish Dietary Guidelines Index (score) & 3.6 & $2 \cdot 4-4.9$ & $4 \cdot 0$ & $2 \cdot 7-5 \cdot 2$ \\
\hline \multicolumn{5}{|l|}{ Intake of vegetables, fruits and juice $(\mathrm{g} / \mathrm{d})$} \\
\hline Vegetables & $142 \cdot 2$ & $42 \cdot 4-321 \cdot 1$ & $164 \cdot 3$ & $46 \cdot 6-370 \cdot 4$ \\
\hline Fruits & $117 \cdot 7$ & $18 \cdot 2-418 \cdot 1$ & 172.4 & $30 \cdot 9-508 \cdot 8$ \\
\hline Juice & 8.6 & $0 \cdot 1-103 \cdot 7$ & $9 \cdot 0$ & $0.1-120 \cdot 4$ \\
\hline \multicolumn{5}{|l|}{ Fish (g/week) } \\
\hline Total & $292 \cdot 1$ & $85 \cdot 0-689 \cdot 4$ & $246 \cdot 7$ & $74 \cdot 7-592 \cdot 3$ \\
\hline Fatty fish* & $105 \cdot 7$ & $17 \cdot 3-322 \cdot 6$ & $85 \cdot 1$ & $13 \cdot 8-280 \cdot 9$ \\
\hline Whole grains $(\mathrm{g} / \mathrm{d})$ & $42 \cdot 4$ & $12 \cdot 0-86 \cdot 6$ & 34.2 & $10 \cdot 6-75 \cdot 8$ \\
\hline Red and processed meat (g/week) & 973.0 & $466 \cdot 9-1783 \cdot 5$ & $585 \cdot 8$ & $244 \cdot 3-1097 \cdot 5$ \\
\hline \multicolumn{5}{|l|}{ Dairy $(g / d)$} \\
\hline Low-fat dairy $\dagger$ & $154 \cdot 0$ & $17 \cdot 8-919.5$ & $201 \cdot 7$ & $17 \cdot 8-760 \cdot 0$ \\
\hline High-fat dairy & $64 \cdot 1$ & $18.6-517.9$ & $65 \cdot 3$ & $19 \cdot 5-317 \cdot 6$ \\
\hline Sodium chloride (table salt; g/d) & $9 \cdot 0$ & $5 \cdot 6-14.0$ & $7 \cdot 0$ & $4.3-10 \cdot 8$ \\
\hline Added sugar (E\%) & $5 \cdot 5$ & $1 \cdot 7-13 \cdot 7$ & $6 \cdot 1$ & $2 \cdot 0-14 \cdot 8$ \\
\hline Water incl. tea and coffee (litres/d) & 1.7 & $0.8-2.9$ & $2 \cdot 0$ & $1 \cdot 0-3 \cdot 2$ \\
\hline Energy (MJ) & 9.9 & $6 \cdot 4-14.9$ & 8.0 & $5 \cdot 1-12 \cdot 3$ \\
\hline \multicolumn{5}{|l|}{ Fat (E\%) } \\
\hline Total & $36 \cdot 5$ & $27 \cdot 5-43 \cdot 7$ & $34 \cdot 1$ & $24.9-41 \cdot 8$ \\
\hline Saturated fat & 13.9 & $9.5-17.9$ & $13 \cdot 1$ & $8 \cdot 6-17 \cdot 6$ \\
\hline Protein $(E \%)$ & 17.9 & $14 \cdot 1-22 \cdot 2$ & $17 \cdot 7$ & $13 \cdot 7-22 \cdot 2$ \\
\hline Carbohydrates (E\%) & $45 \cdot 6$ & $37 \cdot 2-55 \cdot 3$ & $48 \cdot 2$ & $39.5-58.4$ \\
\hline Alcohol $(\mathrm{g} / \mathrm{d})$ & $19 \cdot 4$ & $1.7-80 \cdot 2$ & $9 \cdot 3$ & $0.4-41.6$ \\
\hline Alcohol abstinence (\%) & 1.7 & - & 2.6 & - \\
\hline Age (years) & $55 \cdot 9$ & $50 \cdot 7-64 \cdot 2$ & $56 \cdot 2$ & $50 \cdot 8-64 \cdot 2$ \\
\hline BMl at baseline $\left(\mathrm{kg} / \mathrm{m}^{2}\right)$ & $26 \cdot 1$ & $21 \cdot 5-32 \cdot 9$ & $24 \cdot 8$ & $19 \cdot 9-33.8$ \\
\hline Waist circumference at baseline $(\mathrm{cm})$ & 95 & $81-113$ & 80 & $67-103$ \\
\hline \multicolumn{5}{|l|}{ Moderate-to-vigorous physical activity } \\
\hline Yes $(\%)$ & 79 & - & 84 & - \\
\hline Duration (h/week) & $2 \cdot 0$ & $0.0-11.0$ & 2.5 & $0.0-10.5$ \\
\hline \multicolumn{5}{|l|}{ Smoking (\%) } \\
\hline Never & 26 & - & 44 & - \\
\hline Former & 34 & - & 23 & - \\
\hline Current & 40 & - & 33 & - \\
\hline \multicolumn{5}{|l|}{ Education (\%) } \\
\hline$\leq 7$ years & 34 & - & 31 & - \\
\hline $8-10$ years & 42 & - & 50 & - \\
\hline$>10$ years & 24 & - & 19 & - \\
\hline \multicolumn{5}{|l|}{ Hypertension (\%) } \\
\hline Yes & 15 & - & 17 & - \\
\hline No & 69 & - & 72 & - \\
\hline Don't know & 16 & - & 11 & - \\
\hline \multicolumn{5}{|l|}{ Hypercholesterolaemia (\%) } \\
\hline Yes & 8 & - & 6 & - \\
\hline No & 51 & - & 50 & - \\
\hline Don’t know & 41 & - & 44 & - \\
\hline \multicolumn{5}{|l|}{ Diabetes (\%) } \\
\hline Yes & 3 & - & 2 & - \\
\hline No & 92 & - & 94 & - \\
\hline Don't know & 5 & - & 4 & - \\
\hline
\end{tabular}

E \%, energy percentage.

Values are medians with 5th-95th percentiles (P5-P95) unless otherwise indicated.

*Defined as fish containing $>1 \mathrm{~g} n$-3 PUFA $/ 100 \mathrm{~g}$; includes trout, salmon, herring, mackerel and lumpfish roe.

†Includes skimmed $(0.5 \mathrm{~g}$ fat $/ 100 \mathrm{~g}$ product) and semi-skimmed milk ( $1.5 \mathrm{~g}$ fat $/ 100 \mathrm{~g}$ product), buttermilk ( $0.5 \mathrm{~g}$ fat $/ 100 \mathrm{~g} \mathrm{product)}$, low-fat yoghurt ( $1.5 \mathrm{~g} \mathrm{fat} / 100 \mathrm{~g}$ product), cottage cheese $(5 \mathrm{~g} \mathrm{fat} / 100 \mathrm{~g}$ product), cheese, firm ( $16 \mathrm{~g} \mathrm{fat} / 100 \mathrm{~g}$ product), low-fat ice cream (3 g fat/ $100 \mathrm{~g}$ product), processed cheese $(17 \mathrm{~g}$ fat $/ 100 \mathrm{~g}$ product) and unripened smoked cheese $(0.5 \mathrm{~g}$ fat $/ 100 \mathrm{~g} \mathrm{product})$.

†Includes whole milk ( $3.5 \mathrm{~g}$ fat $/ 100 \mathrm{~g}$ product), whole milk yoghurt ( $3.5 \mathrm{~g}$ fat $/ 100 \mathrm{~g}$ product), cream ( $13 \mathrm{or} 38 \mathrm{~g}$ fat $/ 100 \mathrm{~g} \mathrm{product})$, cheese, firm $(25 \mathrm{~g}$ fat $/ 100 \mathrm{~g}$ product), brie $(28 \mathrm{~g}$ fat $/ 100 \mathrm{~g}$ product), camembert $(22 \mathrm{~g}$ fat $/ 100 \mathrm{~g}$ product), Roquefort/Danish blue (30 g fat $/ 100 \mathrm{~g}$ product), cream cheese ( $37 \mathrm{~g} \mathrm{fat} / 100 \mathrm{~g}$ product), ice cream $(10 \mathrm{~g}$ fat $/ 100 \mathrm{~g}$ product) and unripened smoked cheese (10 g fat $/ 100 \mathrm{~g}$ product).

cubic splines, which limits the possibilities of residual confounding from these risk factors ${ }^{(30)}$. In previous studies of diet quality, relative risks have been consistently attenuated after adjustment for age, BMI, physical activity, smoking and education ${ }^{(31)}$. We also found that the associations between the Danish Dietary Guidelines Index and risk of MI were attenuated after adjustment for potential confounders (model 1b). Since BMI may be considered an 


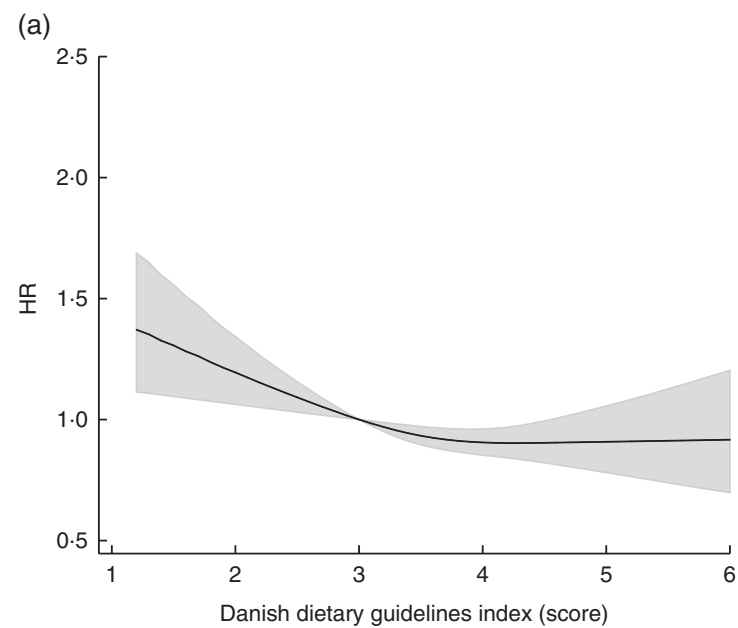

(b)

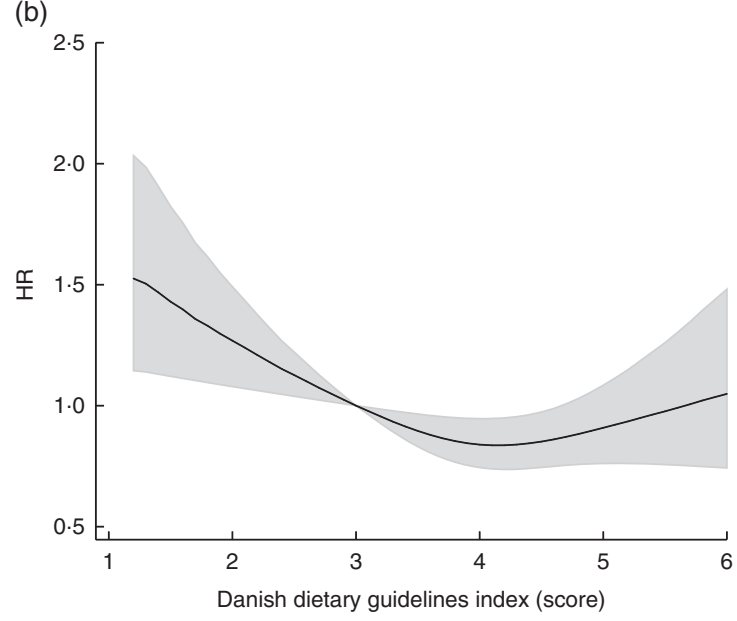

Fig. 2 Hazard ratio (HR) of myocardial infarction across the Danish Dietary Guidelines Index, with a score of 3 as reference, among Danish men (a) and women (b) ( $n 55021$ ) from the Diet, Cancer and Health study. The solid line is the $\mathrm{HR}$ and the shaded area is the $95 \% \mathrm{Cl}$. The Danish Dietary Guidelines Index was modelled using restricted cubic splines with three knots and model $1 \mathrm{~b}$, which adjusted for baseline age, alcohol intake, alcohol abstinence, physical activity, smoking and education, and was stratified by date of enrolment intermediate variable we did not adjust for it in our main model. However, the association between the Danish Dietary Guidelines Index and risk of MI was also present after adjustment for BMI and other potential intermediate variables (model 2).

A plateau was observed in the association between Danish Dietary Guidelines Index score and risk of MI indicating that no further effect on MI risk is gained by adherence to more than four guidelines. However, fewer than $7 \%$ of the study population obtained a score of $\geq 5$ and the CI for this category is therefore wide. Those who have adapted a very healthy diet may be subjects with underlying diseases or family predisposition to CVD. A higher proportion among both men and women with a score of $\geq 5$ reported hypertension, hypercholesterolaemia and diabetes at entry to the study compared with participants with a score of $<5$. Thus, confounding by indication might explain why we find indications of a higher risk of MI among participants with a score $\geq 5$ compared with participants with a score of $4-<5$. However, the same pattern was observed when the analysis was stratified by baseline self-reported disease.

Many different indices of diet quality exist and they have been applied in different study populations using different study designs, which makes comparison across studies difficult ${ }^{(23,32,33)}$. In addition, national food-based dietary guidelines reflect national dietary habits and may not be applicable across different populations. However, since dietary guidelines are generally also based on the available scientific evidence on diet and non-communicable diseases, similarities do exist between national guidelines in different countries. Thus, it is common for national guidelines to include recommendations on a high intake of fruits and vegetables and to recommend low intakes of added sugar and saturated fat ${ }^{(2,34)}$. However, although the major food groups are often similar across countries, there is still no agreement on how to group specific foods. For example, while the majority of European countries including Denmark group potatoes together with grains, some

Table 3 Hazard ratios (HR) and $95 \% \mathrm{Cl}$ of myocardial infarction by adherence to the Danish Dietary Guidelines Index in men ( $n$ 25 961) from the Diet, Cancer and Health study

\begin{tabular}{|c|c|c|c|c|c|c|c|}
\hline & \multirow{2}{*}{$\frac{\text { Cases }}{n}$} & \multicolumn{2}{|c|}{ Model 1a } & \multicolumn{2}{|c|}{ Model $1 b$} & \multicolumn{2}{|c|}{ Model 2} \\
\hline & & $\mathrm{HR}$ & $95 \% \mathrm{Cl}$ & $\mathrm{HR}$ & $95 \% \mathrm{Cl}$ & $\mathrm{HR}$ & $95 \% \mathrm{Cl}$ \\
\hline \multicolumn{8}{|c|}{ Danish Dietary Guidelines Index } \\
\hline Score $<3$ & 570 & 1.00 & Ref. & 1.00 & Ref. & 1.00 & Ref. \\
\hline Score $3-<4$ & 1019 & 0.77 & $0.69,0.85$ & 0.87 & $0.78,0.96$ & 0.85 & $0.77,0.95$ \\
\hline Score $4-<5$ & 484 & 0.66 & $0.58,0.74$ & 0.82 & $0.72,0.93$ & 0.80 & $0.70,0.90$ \\
\hline Score $\geq 5$ & 71 & 0.67 & $0.53,0.86$ & 0.91 & $0.71,1.17$ & 0.86 & $0.67,1.11$ \\
\hline$P$ for trend ${ }^{*}$ & & \multicolumn{2}{|c|}{$<0.001$} & \multicolumn{2}{|c|}{0.009} & \multicolumn{2}{|r|}{0.002} \\
\hline
\end{tabular}

Ref., referent category.

All analyses were stratified by date of enrolment (tertiles).

Model 1a: adjusted for length of follow-up (i.e. baseline age).

Model 1b: model 1a plus alcohol intake, alcohol abstinence, physical activity, smoking and education

Model 2: model 1b plus baseline BMI, waist circumference, hypertension, hypercholesterolaemia and diabetes.

${ }^{\star}$ Test for trend was performed by including the categorised index as a linear variable in the model. 
Table 4 Hazard ratios (HR) and $95 \% \mathrm{Cl}$ of myocardial infarction by adherence to the Danish Dietary Guidelines Index in women $(n 29060)$ from the Diet, Cancer and Health study

\begin{tabular}{|c|c|c|c|c|c|c|c|}
\hline & \multirow{2}{*}{$\frac{\text { Cases }}{n}$} & \multicolumn{2}{|c|}{ Model 1a } & \multicolumn{2}{|c|}{ Model 1b } & \multicolumn{2}{|c|}{ Model 2} \\
\hline & & HR & $95 \% \mathrm{Cl}$ & $\mathrm{HR}$ & $95 \% \mathrm{Cl}$ & $\mathrm{HR}$ & $95 \% \mathrm{Cl}$ \\
\hline \multicolumn{8}{|c|}{ Danish Dietary Guidelines Index } \\
\hline Score $<3$ & 143 & 1.00 & Ref. & 1.00 & Ref. & 1.00 & Ref. \\
\hline Score $3-<4$ & 361 & 0.60 & $0.49,0.73$ & 0.76 & $0.63,0.93$ & 0.74 & $0.60,0.89$ \\
\hline Score $4-<5$ & 316 & 0.48 & $0.40,0.59$ & 0.74 & $0.60,0.91$ & 0.69 & $0.57,0.85$ \\
\hline Score $\geq 5$ & 82 & 0.52 & $0.39,0.68$ & 0.90 & $0.68,1.20$ & 0.83 & $0.62,1.10$ \\
\hline$P$ for trend ${ }^{*}$ & & \multicolumn{2}{|c|}{$<0.001$} & \multicolumn{2}{|c|}{0.214} & \multicolumn{2}{|c|}{0.051} \\
\hline
\end{tabular}

Ref., referent category.

All analyses were stratified by date of enrolment (tertiles).

Model 1a: adjusted for length of follow-up (i.e. baseline age).

Model 1b: model 1a plus alcohol intake, alcohol abstinence, physical activity, smoking and education.

Model 2: model 1b plus baseline BMI, waist circumference, hypertension, hypercholesterolaemia and diabetes.

${ }^{*}$ Test for trend was performed by including the categorised index as a linear variable in the model.

countries consider potatoes as vegetables ${ }^{(2)}$. This further contributes to difficulties in comparing studies of dietary guidelines from different countries, and warrants national studies of food-based dietary guidelines.

Numerous foods and nutrients have been associated with risk of CHD including fruits, vegetables, fish and whole grains, which are all incorporated in the Danish food-based dietary guidelines ${ }^{(35-38)}$. It is therefore not surprising that adherence to the 2013 Danish food-based dietary guidelines was inversely associated with the risk of MI. Yet, previous cohort studies in other countries with national dietary guidelines similar to the Danish foodbased dietary guidelines have not unequivocally found adherence to be associated with lower risk of CVD ${ }^{(39-41)}$. Nevertheless, adherence to the 2005 Swedish dietary guidelines, which are based on the Nordic Nutrition Recommendations, was associated with lower risk of $\mathrm{CVD}^{(41)}$. Diet quality measured with an index based on the 1994 Danish food-based dietary guidelines has also been inversely associated with absolute risk of IHD (the Copenhagen Risk Score), total cholesterol, LDL cholesterol, TAG and homocysteine in a cross-sectional study ${ }^{(11)}$.

In accordance with studies in other Danish cohorts of previous editions of the Danish food-based dietary guidelines $^{(6,7)}$, we found that compliance with the 2013 Danish food-based dietary guidelines was low. Only an infinitesimal $0.04 \%$ of the participants complied fully with all six included guidelines, while approximately $7 \%$ complied with at least five of the guidelines. The only exception was the guideline to eat less sugar, where nearly $85 \%$ of the Diet, Cancer and Health cohort reported an intake below the maximum recommended intake of $10 \%$ of energy, which may be explained by a low consumption of sugar-sweetened beverages in the recruited age groups. The lowest compliance was seen for intake of fruits and vegetables and intake of whole grains, where the proportion of compliers was less than $10 \%$. The recommendation for a high intake of fruits and vegetables has been part of the Danish food-based dietary guidelines since the 1994 edition, whereas the recommendation on whole grains is relatively new and was first included in the guidelines in 2009. In that connection it may be noted that the dietary data in our study were collected between 1993 and 1997, and the intake of whole grains may have increased since then due to a larger focus on whole grains in the media and a greater supply of wholegrain products.

The individual components in the Danish Dietary Guidelines Index were scored proportionally to the recommended intake when constructing the total index. It may be considered a limitation with the scoring that dishes and composite foods were reported as not fully continuous frequencies in the FFQ and then disaggregated into separate foods, which were translated into a continuous value between 0 and 1 . The proportional scoring method was chosen over a simpler binary approach to avoid low discriminating power, and thus low contribution to the overall index, for items where only a small proportion of the participants met the recommendation. Still, using this approach the component for added sugar intake contributed little to the total score, since a very high proportion of the participants met this guideline. In the supplementary analyses of the individual guidelines, items were scored dichotomously, thus only given points for full compliance, to let the coefficients have a simple interpretation. In general, inverse or null associations were observed between adherence to the individual dietary guidelines and risk of MI. A positive association was observed between compliance with the guideline to eat less saturated fat and risk of MI, which is in the opposite direction of what would be expected. However, these supplementary analyses do not take substitutions into account, and, as has been observed in other studies, it may be important what macronutrient replaces saturated fat with regard to risk of $\mathrm{CHD}^{(42)}$.

Total energy intake was not taken into account when constructing the majority of components comprising the Danish Dietary Guidelines Index since the recommendations in the 2013 Danish food-based dietary guidelines are not expressed relative to energy intake in the official pamphlet or on the associated website ${ }^{(5,43)}$. Exceptions are 
the components for saturated fat and added sugar, where scores were calculated based on the energy percentages stated in the Nordic Nutrition Recommendations. As a result, subjects with a high energy intake will more easily meet the recommendations for intakes of fruits and vegetables, fish and whole grains, and thus receive a high score, although the quality of their diet may not be healthier than that of individuals with lower energy requirements. This could introduce confounding and it may be argued that total energy should be adjusted for in the Cox regression model. However, if total energy intake is added to the model, unspecified food substitutions would be introduced, obscuring the interpretation of the results. For these reasons, total energy intake was not allowed for when constructing the dietary index nor adjusted for in the analyses.

\section{Conclusion}

In conclusion, we found that adherence to the national Danish food-based dietary guidelines was associated with a lower risk of MI and our study thus supports the effectiveness of the 2013 Danish food-based dietary guidelines in prevention of MI in the general population. Food-based dietary guidelines aim to ensure the nutrient needs of the general population, promote better health and reduce the risk of non-communicable diseases. Future cohort studies are needed to elucidate the effectiveness of the 2013 Danish food-based dietary guidelines in reducing the risk of other major chronic diseases.

\section{Acknowledgements}

Acknowledgements: The authors thank the Danish Cancer Society and the staff at the Diet, Cancer and Health study for the collection and administration of data. Financial support: This work is part of the project 'Diet and prevention of ischemic heart disease: a translational approach' (DIPI; http://www.dipi.dk), which is supported by the Danish Council for Strategic Research (today, Innovation Fund Denmark) (contract number 060300488B). The Danish Council for Strategic Research had no role in the design, analysis or writing of this article. Conflict of interest: None. Authorship: C.P.H., C.C.D. and K.O. formulated the research question and designed the study; A.T. and K.O. collected the data; C.P.H. conducted the statistical analyses and drafted the manuscript; C.P.H., C.C.D., K.O., I.T., E.T.P., M.U.J. and K.O. contributed to the interpretation of the results and the critical revision of the manuscript. All authors read and approved the final manuscript. Etbics of buman subject participation: This study was conducted according to the guidelines laid down in the Declaration of Helsinki and all procedures involving human subjects were approved by the ethics committees in Aarhus and Copenhagen. Written informed consent was obtained from all subjects.

\section{Supplementary material}

To view supplementary material for this article, please visit https://doi.org/10.1017/S1368980017003822

\section{References}

1. World Health Organization (1998) Preparation and Use of Food-Based Dietary Guidelines. Report of a Joint FAO/WHO Consultation. WHO Technical Report Series no. 880. Geneva: WHO.

2. Montagnese C, Santarpia L, Buonifacio M et al. (2015) European food-based dietary guidelines: a comparison and update. Nutrition 31, 908-915.

3. Tetens I, Andersen LB, Astrup A et al. (2013) Evidensgrundlaget for Danske Råd om Kost og Fysisk Aktivitet (The Evidence-Base for the Danish Guidelines for Diet and Physical Activity). Søborg: DTU Fødevareinstituttet (in Danish with an English summary).

4. Nordic Council of Ministers (2014) Nordic Nutrition Recommendations 2012. Integrating Nutrition and Physical Activity, 5th ed. Copenhagen: Nordic Council of Ministers.

5. Fødevarestyrelsen (2013) De Officielle Kostråd (The Official Dietary Guidelines), 1st ed. Glostrup: Fødevarestyrelsen.

6. Knudsen VK, Fagt S, Trolle E et al. (2012) Evaluation of dietary intake in Danish adults by means of an index based on food-based dietary guidelines. Food Nutr Res 56, 17129.

7. Biltoft-Jensen A, Fagt S, Groth MV et al. (2008) The intake of saturated fat and dietary fibre: a possible indicator of diet quality. Br J Nutr 100, 624-632.

8. Lyhne N, Christensen T, Groth MV et al. (2005) Danskernes Kostvaner 2000-2002. Hovedresultater (Dietary Habits in Denmark 2000-2002. Main Results), 1st ed. Søborg: Danmarks Fødevareforskning (in Danish with an English summary).

9. Pedersen AN, Sisse F, Groth MV et al. (2010) Danskernes Kostvaner 2003-2008. Hovedresultater (Dietary Habits in Denmark 2003-2008. Main Results), 1st ed. Søborg: DTU Fødevareinstituttet (in Danish with an English summary).

10. Willett WC \& McCullough ML (2008) Dietary pattern analysis for the evaluation of dietary guidelines. Asia Pac J Clin Nutr 17, Suppl. 1, 75-78.

11. Toft U, Kristoffersen LH, Lau C et al. (2007) The dietary quality score: validation and association with cardiovascular risk factors: the Inter99 study. Eur J Clin Nutr 61, 270-278.

12. Osler M, Helms Andreasen A, Heitmann B et al. (2002) Food intake patterns and risk of coronary heart disease: a prospective cohort study examining the use of traditional scoring techniques. Eur J Clin Nutr 56, 568-574.

13. World Health Organization (2014) The top 10 causes of death. Fact sheet no. 310. http://www.who.int/mediacentre/factsheets/fs310/en/ (accessed June 2015).

14. Tjønneland A, Olsen A, Boll K et al. (2007) Study design, exposure variables, and socioeconomic determinants of participation in Diet, Cancer and Health: a population-based prospective cohort study of 57,053 men and women in Denmark. Scand J Public Health 35, 432-441.

15. Overvad K, Tjønneland A, Haraldsdottir J et al. (1991) Development of a semiquantitative food frequency questionnaire to assess food, energy and nutrient intake in Denmark. Int J Epidemiol 20, 900-905. 
16. Møller A \& Saxholt E (1996) Levnedsmiddeltabeller (Food Composition Tables), 4th ed. Søborg: Levned middelstyrelsen.

17. Tjønneland A, Haraldsdottir J, Overvad K et al. (1992) Influence of individually estimated portion size data on the validity of a semiquantitative food frequency questionnaire. Int J Epidemiol 21, 770-777.

18. Tjønneland A, Overvad K, Haraldsdottir J et al. (1991) Validation of a semiquantitative food frequency questionnaire developed in Denmark. Int J Epidemiol 20, 906-912.

19. American Association of Cereal Chemists (1999) Whole grains. http://www.aaccnet.org/initiatives/definitions/pages/ wholegrain.aspx (accessed October 2016).

20. Kyrø C, Skeie G, Dragsted LO et al. (2012) Intake of whole grain in Scandinavia: intake, sources and compliance with new national recommendations. Scand J Public Health $\mathbf{4 0}$, 76-84.

21. Fødevarestyrelsen (2013) Hvad Tæller Med i 6 om Dagen? (What are included in 6 a day?) http://www.altomkost.dk/ Anbefalinger/De_officielle_kostraad/Spis_frugt_og_mange_ gronsager/Hvad_taeller_med_i_6_om_dagen.htm (accessed June 2014).

22. Thiele S, Mensink GB \& Beitz R (2004) Determinants of diet quality. Public Health Nutr 7, 29-37.

23. Waijers PM, Feskens EJ \& Ocke MC (2007) A critical review of predefined diet quality scores. Br J Nutr 97, 219-231.

24. Schmidt M, Schmidt SA, Sandegaard JL et al. (2015) The Danish National Patient Registry: a review of content, data quality, and research potential. Clin Epidemiol 7, 449-490.

25. Helweg-Larsen K (2011) The Danish register of causes of death. Scand J Public Health 39, 26-29.

26. Luepker RV, Apple FS, Christenson RH et al. (2003) Case definitions for acute coronary heart disease in epidemiology and clinical research studies: a statement from the AHA Council on Epidemiology and Prevention; AHA Statistics Committee; World Heart Federation Council on Epidemiology and Prevention; the European Society of Cardiology Working Group on Epidemiology and Prevention; Centers for Disease Control and Prevention; and the National Heart, Lung, and Blood Institute. Circulation 108, 2543-2549.

27. Joensen AM, Jensen MK, Overvad K et al. (2009) Predictive values of acute coronary syndrome discharge diagnoses differed in the Danish National Patient Registry. J Clin Epidemiol 62, 188-194.

28. Harrell FE (2001) Regression Modeling Strategies. With Applications to Linear Models, Logistic Regression and Survival Analysis, 1st ed. New York: Springer.

29. Cobb LK, Anderson CA, Elliott P et al. (2014) Methodological issues in cohort studies that relate sodium intake to cardiovascular disease outcomes: a science advisory from the American Heart Association. Circulation 129, $1173-1186$.

30. Greenland S (1995) Dose-response and trend analysis in epidemiology: alternatives to categorical analysis. Epidemiology 6, 356-365.

31. Wirt A \& Collins CE (2009) Diet quality - what is it and does it matter? Public Health Nutr 12, 2473-2492.

32. Fransen HP \& Ocke MC (2008) Indices of diet quality. Curr Opin Clin Nutr Metab Care 11, 559-565.

33. Wirfalt E, Drake I \& Wallstrom P (2013) What do review papers conclude about food and dietary patterns? Food Nutr Res 2013, 57.

34. World Health Organization (2003) Food Based Dietary Guidelines in the WHO European Region. Copenhagen: WHO.

35. Mente A, de Koning L, Shannon HS et al. (2009) A systematic review of the evidence supporting a causal link between dietary factors and coronary heart disease. Arch Intern Med 169, 659-669.

36. He FJ, Nowson CA, Lucas M et al. (2007) Increased consumption of fruit and vegetables is related to a reduced risk of coronary heart disease: meta-analysis of cohort studies. J Hum Hypertens 21, 717-728.

37. Zheng J, Huang T, Yu Y et al. (2012) Fish consumption and CHD mortality: an updated meta-analysis of seventeen cohort studies. Public Health Nutr 15, 725-737.

38. Aune D, Keum N, Giovannucci E et al. (2016) Whole grain consumption and risk of cardiovascular disease, cancer, and all cause and cause specific mortality: systematic review and dose-response meta-analysis of prospective studies. BMJ 353, i2716.

39. Struijk EA, May AM, Wezenbeek NL et al. (2014) Adherence to dietary guidelines and cardiovascular disease risk in the EPIC-NL cohort. Int J Cardiol 176, 354-359.

40. von Ruesten A, Illner AK, Buijsse B et al. (2010) Adherence to recommendations of the German food pyramid and risk of chronic diseases: results from the EPIC-Potsdam study. Eur J Clin Nutr 64, 1251-1259.

41. Hlebowicz J, Drake I, Gullberg B et al. (2013) A high diet quality is associated with lower incidence of cardiovascular events in the Malmo diet and cancer cohort. PLoS One 8, e71095.

42. Jakobsen MU, O'Reilly EJ, Heitmann BL et al. (2009) Major types of dietary fat and risk of coronary heart disease: a pooled analysis of 11 cohort studies. Am J Clin Nutr 89, $1425-1432$.

43. Fødevarestyrelsen (2013) De Officielle Kostråd (The Official Dietary Guidelines). http://altomkost.dk/deofficielleanbe falingertilensundlivsstil/de-officielle-kostraad/ (accessed June 2014). 